\title{
Optimization of Process Design Problems Using Differential Evolution Algorithm
}

\author{
A.M. Gujarathia ${ }^{*}$, G. Vakili-Nezhaada and M. Vatani ${ }^{b}$ \\ $a^{*}$ Department of Petroleum and Chemical Engineering, College of Engineering, Sultan Qaboos University, \\ P.O. Box. 33, Muscat 123, Sultanate of Oman. \\ ${ }^{b}$ Department of Chemical Engineering, Amirkabir University of Technology (Tehran Polytechnic), Hafez Ave., P.O. Box 15875- \\ 4413, Tehran, Iran.
}

Received 15 September 2015; Accepted 29 November 2015

\begin{abstract}
A modified differential evolution algorithm (MDE) has been used for solving different process related design problems (namely calculation of the NRTL and Two-Suffix Margules activity coefficient models parameters in 20 ternary extraction systems including different ionic liquids and reactor network design problem). The obtained results, in terms of root mean square deviations (rmsd) for these models are satisfactory, with the overall values of 0.0023 and 0.0170 for 169 tie-lines for NRTL and Two-Suffix Margules models, respectively. The results showed that the MDE algorithm results in better solutions compared to the previous work based on genetic algorithm (GA) for correlating liquid-liquid equilibrium (LLE) data in these systems. MDE also outperformed DE algorithm when tested on reactor network design problem with respect to convergence and speed.
\end{abstract}

Keywords: NRTL, Two-suffix margules, Parameter estimation, Ionic liquid, Optimization.

$$
\text { تحقيق الحل الأمثل لمشاكل تصميم العمليات باستخدام منهاج النمو التفاضلي المعدل }
$$

الملخص: تم استخدام منهاج النمو التفاضلي المعدل (MDE) من أجل حل العمليات المختلفة المتعلقة بهشاكل التصهيم (أي

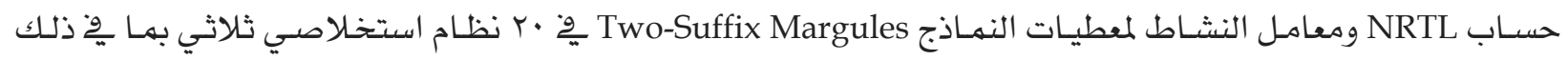

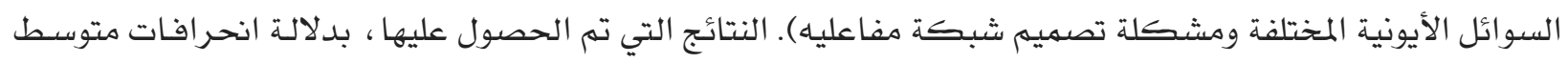

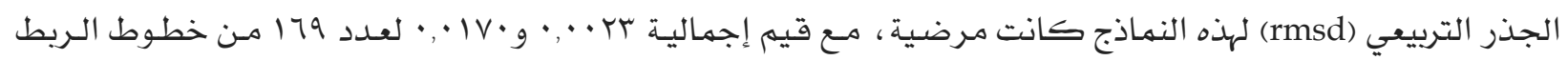

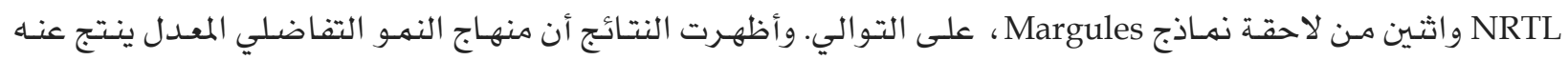

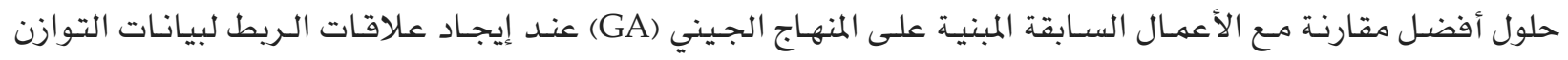

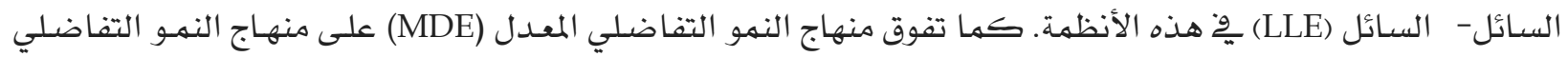
عند اختباره على مشكلة تصميم شبكة مفاعليه وذلك فيما يتعلق بالوصول للحل وتعجيل هذا الوصول.

الكلمات المفتاحية: النهو التفاضلي المعدل (MDE)، NRTL، Margules، تقدير المعطيات، توازن السائل- السائل، السوائل الأيونية ، تصميم شبكة مفاعليه، تحقيق الحل الأمثل.

\footnotetext{
*Corresponding author's e-mail: ashishg@squ.edu.om
} 


\section{Nomenclature}

List of symbols

\begin{tabular}{|c|c|}
\hline$A$ & interaction parameter \\
\hline CR & crossover constant \\
\hline $\mathrm{F}$ & Scaling factor \\
\hline$F_{o b j}$ & Objective function \\
\hline G & Energy parameter \\
\hline Gmax & maximum number of generations \\
\hline K & Distribution ratio \\
\hline$L$ & Molar split ratio \\
\hline M & Number of tie lines \\
\hline NP & Population size \\
\hline$R$ & Universal gas constant \\
\hline$T$ & Absolute temperature \\
\hline$x$ & Liquid-phase mole fraction \\
\hline Z & Overall, or make-up molar fraction \\
\hline
\end{tabular}

Greek letters

$$
\begin{array}{ll}
\gamma & \text { activity coefficient } \\
\tau & \text { energy parameter } \\
a & \text { non-randomness parameter }
\end{array}
$$

Superscript and Subscripts

cal calculated value

exp experimental value

I, II two liquid phases at equilibrium

$i, j, k$ component, phase and tie line respectively

$1,2,3$ aromatic, aliphatic and ionic liquid respectively 


\section{Introduction}

Phase equilibria play an important role in the synthesis, development, design, and control of chemical and petroleum engineering processes. Phase behavior is often analyzed using equation of state and activity coefficient models. Though lots of data is available in literature which correlate both the model and experimental data, estimation of accurate model parameters still remain a challenge. Local optimization methods (such as Newtons method or least square techniques, etc.) are often used to solve phase equilibrium problems. But because the search space is highly nonlinear consisting of local and global minima's, the local methods may converge to a local optimum point (Stragevitch and Davila 1997; Sahoo et al. 2006). In recent past the stochastic optimization techniques (such as differential evolution (DE), genetic algorithms (GA), simulated annealing (SA), particle swarm algorithm, etc.) (Holland 1992; Kirkpatrick et al. 1983; Price et al. 2005) have shown considerable potential in solving complex engineering problems (such as phase equilibrium problems, reaction engineering problems, process calculations related optimization problems etc.). Liquid-Liquid-Equilibrium (LLE) has remained a very challenging problem for non-ideal liquid solutions such as ionic liquids (ILs). ILs are green solvent and they have shown potential applications in many separation processes (Lei et al. 2009). For designing any separation processes using ionic liquids, the accurate estimation of activity coefficient parameters is of vital importance. As a quick review on these problems we may refer to the following works:

GA has been utilized for estimation of the parameters for two well-known activity coefficient models (ie. NRTL and UNIQUAC) (Singh et al. 2005). They proved that their results were better than local search methods. In another study (Sahoo et al. 2006; Sahoo et al. 2007), GA was used to estimate ternary, quaternary and quinary LLE interaction parameters for NRTL and UNIQUAC models. It was reported that GA results were better than other techniques. Another group of authors (Rashtchian et al. 2007) also used a stochastic method (genetic algorithm) for phase behavior of multiphase and multicomponent systems. They calculated the binary interaction parameters of UNIQUAC, NRTL and Wilson models for a number of systems. They also reported their data and compared their data for various systems (including vapor liquid equilibrium, vapor-liquidliquid equilibrium, and liquid-liquid equilibrium) form the literature. In some other studies, GA was successfully applied for estimation of interaction parameters of other complex models for systems of LLE containing ionic liquids and also for modeling of viscosity of crude oil binary blends (Vatani et al. 2012; Vakili-Nezhaad et al. 2013; Vakili-Nezhaad et al. 2014; Al-Maamari et al. 2015).

Modified DE algorithm is used for calculation of two complex problems. The performance of MDE algorithm is also explored by comparing its output with other algorithms. Parameters of two activation coefficient models (which include NRTL and TwoSuffix-Margules model) are calculated using experimental data having 20 sets of ternary liquid systems having 20 different ILs. The reactor network problem is also solved and both the speed and accuracy aspects of MDE algorithm are reported. The statistical parameters of the models including root mean square deviation for the above mentioned set of ternary systems is reported. Comparison of the results obtained using MDE with our previous work based on GA (Vatani et al. 2012) shows that MDE is a very reliable algorithm in parameter estimation problems which can give more accurate results compared to GA. Abbreviation, full names and list of ternary ionic liquid systems used in this study is given in Table 1.

\section{Problem formulation}

\subsection{The LLE Modeling}

The LLE modeling is based on thermodynamic equilibrium condition for mole fractions and activity coefficient between the aliphatic rich phase (I) and the IL rich phase (II).

$$
\left(x_{i} \gamma_{i}\right)^{\mathrm{I}}=\left(x_{i} \gamma_{i}\right)^{\Pi}
$$

The molar component balances lead to the following equation:

$$
Z_{i}=x_{i}^{\mathrm{I}} L+x_{i}^{\Pi}(1-L)
$$

where $x, \gamma, Z$ and $\mathrm{L}$ are mole fraction, activity coefficient, the overall mole fraction and the molar split ratio respectively, and the subscript $i$ denotes the components.

Considering the distribution ratio of component as below:

$$
K_{i}=\frac{x_{i}^{\mathrm{I}}}{x_{i}^{\mathrm{II}}}
$$

and solving Eq. (3) with Eq. (2), the Rachford-Rice equation (Seader and Henley 2006) is concluded as: 
Table 1. Abbreviation, full name and list of ternary ionic liquid systems used in this work.

\begin{tabular}{|c|c|c|c|c|c|c|}
\hline Abbreviation & Full name of ionic liquid & $\begin{array}{l}\text { Sys. } \\
\text { No. }\end{array}$ & Name of ternary systems & $T(\mathrm{~K})$ & $\begin{array}{l}\text { Tie- } \\
\text { line }\end{array}$ & Ref. \\
\hline [mebupy][BF $\left[\mathrm{BF}_{4}\right.$ & 4-methyl-N-butylpyridinium tetrafluoroborate & 1 & propylbenzene(1)+hexadecane(2)+[mebupy][BF 4$](3)$ & 313.00 & 10 & Alkhaldi et al. 2011 \\
\hline [3-mebupy][DCA] & 3-methyl-N-butyl pyridiniumdicyanamide & 2 & benzene(1)+hexane(2)+[3-mebupy][DCA](3) & 303.15 & 11 & Hansmeier et al. 2010a \\
\hline [emim] $\left[\mathrm{ESO}_{4}\right]$ & 1-ethyl-3-methylimidazolium ethylsulfate & 3 & benzene(1)+hexane(2)+[emim][ESO 4 ](3) & 313.20 & 08 & García et al. 2009 \\
\hline$[\mathrm{bmim}]\left[\mathrm{MSO}_{4}\right]$ & 1-butyl-3-methylimidazolium methylsulfate & 4 & Benzene(1)+Hexane(2)+[bmim] $\left[\mathrm{MSO}_{4}\right](3)$ & 328.20 & 08 & García 2010a \\
\hline$[\mathrm{bmim}]\left[\mathrm{BF}_{4}\right]$ & 1-butyl-3-methylimidazolium tetrafluoroborate & 5 & Benzene(1)+Heptane(2)+[bmim][BF $](3)$ & 298.15 & 08 & Revelli et al. 2010 \\
\hline [bmim] $\left[\mathrm{NTf}_{2}\right]$ & 1-butyl-3-methylimidazolium bis $\{$ trifluoromethylsulfonyl $\}$ imide & 6 & benzene(1)+octane(2)+[bmim][NTf 2$](3)$ & 298.15 & 13 & Domínguez et al. 2011 \\
\hline$[\mathrm{bmim}]\left[\mathrm{PF}_{6}\right]$ & 1-butyl-3-methylimidazolium hexafluorophosphate & 7 & benzene(1)+Undecane(2)+[bmim][PF 6$](3)$ & 298.15 & 05 & Maduro and Aznar 2008 \\
\hline [omim][CL] & 1-octyl-3-methylimidazolium chloride & 8 & benzene(1)+Dodecane(2)+[omim][CL](3) & 298.20 & 04 & Letcher and Deenadayalu 2003 \\
\hline$[\mathrm{hmim}]\left[\mathrm{BF}_{4}\right]$ & 1-hexyl-3-methylimidazolium tetrafluoroborate & 9 & 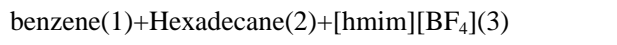 & 298.20 & 09 & Letcher and Reddy 2005 \\
\hline$[\mathrm{pmim}]\left[\mathrm{PF}_{6}\right]$ & 1-propyl-3-methylimidazolium h & 10 & benzene(1)+Cyclohexane(2)+[pmim][PF 6$](3)$ & 298.15 & 08 & Zhou et al. 2012 \\
\hline Ammoeng 102 & $\begin{array}{l}\text { exafluorophosphate } \\
\text { tetraalkyl ammonium sulfate }\end{array}$ & 11 & toluene(1)+heptane(2)+Ammoeng102(3) & 298.15 & 08 & Pereiro and Rodriguez 2009 \\
\hline [bmim][SCN] & 1-butyl-3-methylimidazolium thiocyanate & 12 & Toluene(1)+heptane(2)+[bmim][SCN](3) & 303.15 & 07 & Hansmeier et al. 2010b \\
\hline$[\mathrm{bpy}]\left[\mathrm{BF}_{4}\right]$ & N-butylpyridiniumtetrafluoroborate & 13 & Toluene(1)+heptane(2)+[bpy][BF $]$ ](3) & 313.20 & 08 & García et al. 2010b \\
\hline [EtMe][ImI $\left.{ }_{3}\right]$ & 1-ethyl-3-methylimidazolium triiodide & 14 & Toluene(1)+heptane(2)+[EtMe][ImI $]$ ](3) & 318.15 & 14 & Selvan et al. 2000 \\
\hline [bmim][DCA $]$ & 1-butyl-3-methylimidazolium dicyanamide & 15 & Toluene(1)+heptane(2)+[bmim][DCA](3) & 328.15 & 07 & Hansmeier et al. 2010b \\
\hline [hmim][TCB] & 1-hexyl-3-methylimidazolium tetracyanoborate & 16 & toluene(1)+methylcyclohexane(2)+[hmim][TCB](3) & 293.15 & 09 & Gutierrez et al. 2011 \\
\hline [bmim][TCB] & 1-butyl-3-methylimidazolium tetracyanoborate & 17 & toluene(1)+methylcyclohexane(2)+[bmim][TCB](3) & 313.15 & 09 & Gutierrez et al. 2011 \\
\hline$[\mathrm{omim}]\left[\mathrm{PF}_{6}\right]$ & 1-octyl-3-methylimidazolium hexafluorophosphate & 18 & m-xylene(1)+Nonane(2)+[omim][PF 6 (3) & 298.15 & 04 & Maduro and Aznar 2010 \\
\hline $\mathrm{C}_{2} \mathrm{NTf}_{2}$ & $\begin{array}{l}\text { ethyl(2- } \\
\text { hydroxyethyl)dimethylammoniumbis }\{(\text { trifluomethyl)sulfonyl }\} \text { imide }\end{array}$ & 19 & m-xylene(1)+hexane(2)+[C $\left.{ }_{2} \mathrm{NTf}_{2}\right](3)$ & 298.15 & 10 & Dománska et al. 2007 \\
\hline \multirow[t]{2}{*}{ [dmim][MP] } & 1,3-dimethylimidazolium methylphosphonate & 20 & Thiophene(1)+Heptane(2)+[dmim][MP](3) & 298.15 & 09 & Revelli et al. 2010 \\
\hline & & & Overall & & 169 & \\
\hline
\end{tabular}


$\sum_{i} \frac{Z_{i}\left(1-K_{i}\right)}{1+L\left(K_{i}-1\right)}=0$

Considering Eq. (1), Eq. (3) can be rewritten as $K_{i}=\gamma_{i}^{\mathrm{II}} / \gamma_{i}^{\mathrm{I}}$, where $\gamma_{i}$ is proper activity coefficient models with an appropriate adjustable parameters.

\subsection{The NRTL and Two-Suffix Margules Models}

In the present work, the experimental LLE data were correlated by NRTL and Two-Suffix Margules models (Renon and Prausnitz 1968; Prausnitz et al. 1999). The activity coefficient $\gamma_{i}$ of NRTL model is expressed as:

$\ln \gamma_{i}=\frac{\sum_{j=1}^{m} \tau_{j i} G_{j i} x_{j}}{\sum_{k=1}^{m} G_{k i} X_{k}}+\sum_{j=1}^{m} \frac{x_{j} G_{i j}}{\sum_{k=1}^{m} G_{k j} X_{k}}\left[\tau_{i j}-\frac{\sum_{k=1}^{m} x_{k} \tau_{k j} G_{k j}}{\sum_{k=1}^{m} G_{k j} x_{k}}\right]$

where the binary interaction $A_{i j}$, and nonrandomness parameters $a_{i j}$, have been defined as:

$$
\tau_{i j}=\frac{\Delta g_{i j}}{R T}=\frac{A_{i j}}{T}, G_{i j}=\exp \left(-\alpha_{i j} \tau_{i j}\right)
$$

so in general $A_{i i}=A_{j j}=0, A_{i j} \neq A_{j i}$ and $a_{i j}=a_{j i}$.

Beside NRTL model, the activity coefficients of Two-Suffix Margules model are as below:

$$
\operatorname{Ln} \gamma_{1}=A_{12} x_{2}^{2}+A_{13} x_{3}^{2}+\left(A_{12}+A_{13}-A_{23}\right) x_{2} X_{3}
$$

$$
L n \gamma_{2}=A_{12} x_{1}^{2}+A_{23} x_{3}^{2}+\left(A_{12}+A_{23}-A_{13}\right) x_{1} x_{3}
$$

$$
\operatorname{Ln} \gamma_{3}=A_{13} x_{1}^{2}+A_{23} x_{2}^{2}+\left(A_{13}+A_{23}-A_{12}\right) x_{1} x_{2}
$$

where, $A_{12}, A_{13}$ and $A_{23}$ are the interaction parameters, which were regressed by ternary systems data used in this work.

\subsection{Objective Function and Decision Variables}

The single objective optimization study is considered. The experimental data for 20 ternary extraction systems containing different ionic liquids are used. NRTL and Two-Suffix Margules activity coefficient models parameters are estimated using the modified differential evolution algorithm. In general, parameter estimation is considered as a minimization of an objective function value $\left(F_{o b j}\right)$ (Revelli et al. 2010), which minimizes the deviation between the experimental and calculated mole fractions of the components. This part of study deals with the estimation of thermodynamic activity coefficient models parameters for a ternary set of systems, accordingly the problem is formulated as:

Minimize $\quad F_{o b j}=\left[\sum_{i} \sum_{j} \sum_{k}\left(x_{i, j, k}^{\exp }-x_{i, j, k}^{c a l}\right)\right]$

Lower and uppers bounds of parameters used in this work are given in Table 2. The criterion for comparison between the experimental and calculated data is given by the following equation.

$r m s d=\left[\sum_{i} \sum_{j} \sum_{k}\left(x_{i j k}^{\mathrm{exp}}-x_{i j k}^{c a l}\right)^{2} / 6 M\right]^{1 / 2}$

where, $x$ and $M$ are mole fraction and the number of tie lines and subscripts $i, j$ and $k$ are component, phase, and tie lines respectively.

In this study Reactor Network Design (RND) problem is considered for optimization study. RND problem is optimized using variants of differential evolution algorithms namely, DE and MDE.

\subsection{Reactor Network Design Problem:}

This RND design problem is obtained from Ryoo and Sahinidis (Ryoo and Sahinidis 1995) (see Fig. 1). Two CSTR reactors in sequence having consecutive reactions $(\mathrm{P} \rightarrow \mathrm{Q} \rightarrow \mathrm{R})$ are considered. The intermediate product concentration leaving the second reactor is maximized in this problem.

Both the global and local solutions for this problem are reported in literature (Angira 2006; Babu and Angira 2006). The problem is reformulated by removing the equality constraint (Eqs. 12-15):

$$
k_{2} x_{6} *\left(1+k_{3} x_{5}\right)+k
$$

Maximize. $f=\frac{{ }_{1} x_{5} *\left(1+k_{2} x_{6}\right)}{\left(1+k_{11} x_{5}\right) *\left(1+k_{22} x_{6}\right) *}$

Sub. to: $\quad x_{5}{ }^{0.5}+x_{6}{ }^{0.5} \leq 4$ 
Table 2. Interaction parameters values used in present study for the systems.

\begin{tabular}{lllll}
\hline \multirow{2}{*}{$\begin{array}{l}\text { Component } \\
i-j\end{array}$} & NRTL & & & Margules \\
\cline { 2 - 5 } & $A_{i j}$ & $A_{j i}$ & $a_{i j}$ & $A_{i j}$ \\
\hline $1-2$ & {$[1,2500]$} & {$[-500,2500]$} & {$[0.15,0.5]$} & {$[-10,50]$} \\
$1-3$ & {$[1,2500]$} & {$[-500,2500]$} & {$[0.15,0.5]$} & {$[-10,50]$} \\
$2-3$ & {$[1,2500]$} & {$[1,2500]$} & {$[0.15,0.5]$} & {$[-10,50]$} \\
\hline
\end{tabular}
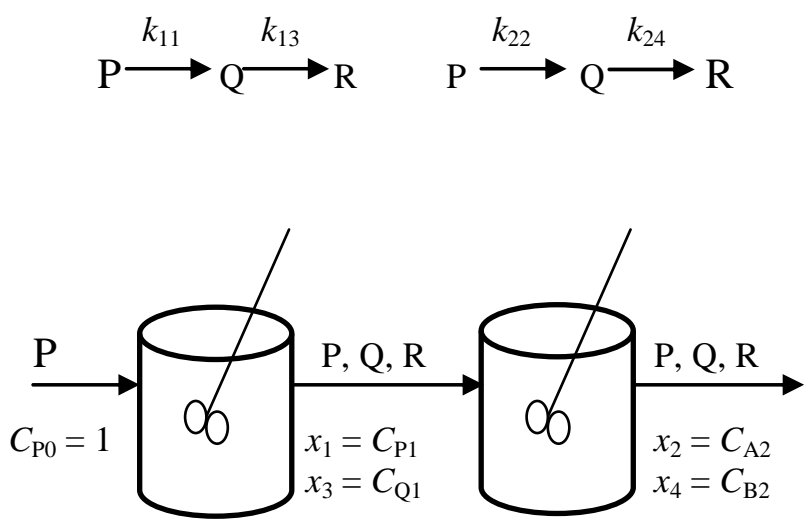

Figure 1. Reactor network design problem.

$10^{-5} \leq x_{5} \leq 16$

$10^{-5} \leq x_{6} \leq 16$

where, $k_{11}=0.09755988, \quad k_{22}=0.99 * k_{1}, \quad k_{13}$ $=0.0391908, k_{24}=0.9 * k_{3}$

In this study, DE and MDE algorithms are used to solve the reformulated problem.

\section{Modified Differential Evolution (MDE)}

The survival of the fittest principle is used in both DE and MDE. Against DE, MDE maintains only one array of variables (bounded by lower and upper bounds). This population gets improved if a better candidate solution is obtained by allowing new solution to take part in the cross over and mutations operations in the same generation. Thus it is observed that number of function evaluations are lowered thus improving the convergence of algorithm. It has been found in the previous studies that an updating the single array continuously enhances the convergence speed leading to less function evaluations as compared to DE (Price et al. 2005). MDE also offers advantages of one array consuming less memory and an improvement on CPU time. Premature convergence can be avoided by wisely/appropriately choosing the key parameters of MDE (such as NP, CR and F) (Fan and Lampinen 2003; Angira and Babu 2006). Both DE and MDE algorithms are widely used in the field of non-linear chemical processes, computational magnetics, process synthesis and design problems, and computational fluid dynamics, etc. (Angira and Babu 2006; Angira 2006; Stumberger et al. 2000; Colaco et al. 2004). Similarly multi-objective optimization strategies of differential algorithms are successfully applied on selected real world optimization problems (such as MOO of LDPE tubular reactor, styrene reactor (both adiabatic and pseudo-isothermal reactor), PTA oxidation process, etc.) (Gujarathi and Babu 2009a; Gujarathi and Babu 2009b; Gujarathi and Babu 2010a; Gujarathi and Babu 2010b; Gujarathi and Babu 2011). These MOO strategies of DE algorithms are in general found to outperform some other existing evolutionary strategies of MOO.

\section{Results and Discussion}

\subsection{Effect of Key Parameters (CR, F, and NP)}

Modified differential evolution is a population based stochastic type of algorithm. It is observed that the outcome of stochastic algorithms, in general, depends on its control parameters. The performance of DE and MDE algorithms depends on key parameters, namely, NP, CR, and F. Three systems (System 1, 6 and 
10) are selected randomly. Table 3 shows the parameter values used in this study. All the

Table 3. Parameter values used in present study.

\begin{tabular}{ll}
\hline Parameter & Value \\
\hline $\begin{array}{l}\text { Population size (NP) } \\
\text { Maximum Number of } \\
\text { generations (Gmax) }\end{array}$ & 150 \\
$\begin{array}{l}\text { Crossover constant (CR) } \\
\text { Scaling Factor (F) }\end{array}$ & 0.8 \\
\hline
\end{tabular}

optimization runs were run for 150 numbers of generations. Various optimization runs are carried out by judiciously varying these control parameters for each of the selected systems. Population size is plotted versus objective function and is shown through Fig. 2a. There is no fixed guideline about the optimum size of population. If the population size is too low, it becomes difficult for an algorithm to converge
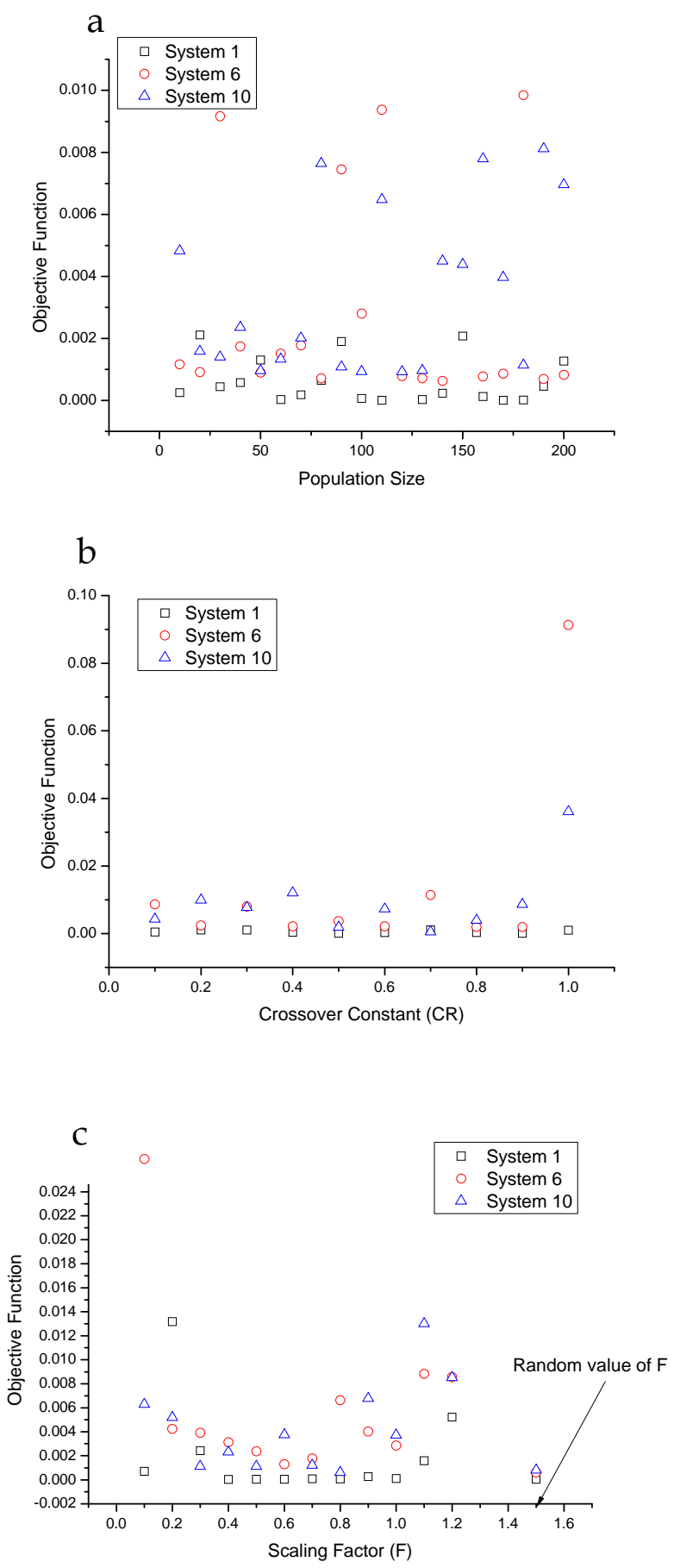

Figure 2. Effects of control parameters a) Population size; b) Crossover constant; and c) Scaling factor. 
optimally. The computation cost increases by increasing the population size. In this optimization study, population specific runs are carried out by varying the population size for each system. Results for three randomly selected systems are plotted and shown in Fig. 2a. Accordingly population size of 120 is selected and is used during the optimization study in this work. Similarly the crossover constant and the scaling factors are also varied and results for three randomly selected systems are shown in Fig. 2b, and Fig. 2c. Similar results could be obtained for all systems in this work.

\subsection{Comparison of MDE, GA and other Methods from Literature}

The MDE algorithm is used to calculate the interaction parameters of NRTL and Two-Suffix Margules activity coefficient models in LLE systems shown in Table 1. Both the optimization and model simulation codes are written and simulated using MATLAB (2009) software. During optimization study, three systems are randomly selected to study the effects of parameters on objective function. The objective function value with respect to generation number is plotted for 3 randomly selected systems. Fig. 3 shows that irrespective of selected system (in this study); the MDE algorithm converges to the minimum function value in less than 90 generations. However, the algorithm is allowed to run for 150 numbers of generations to ensure that the optimum is reached.

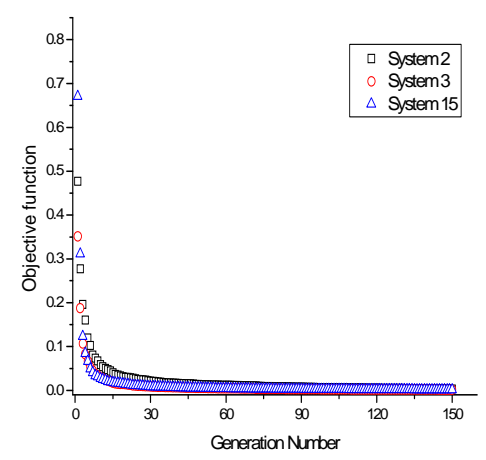

Figure 3. Convergence profile of selected systems using MDE.

Population based stochastic algorithms have a typical feature that they start with population of points and all the points are expected to converge to the optimum points. The results are shown through Table 4 and Table 5. Table 4 shows the calculated parameters of the individual models for each individual system. Table 5 shows the results of rmsd obtained using MDE and GA and other methods form literature. MDE is able to converge to the global optimum having overall rmsd values of 0.0023 and 0.0170 for NRTL and Two-Suffix Margules models. As an example, the experimental and calculated tie-lines were compared in Figs. 4 and 5 for the system No.1.

\subsection{Optimization of CSTR Reactor Design Network}

Table 6 shows the results obtained using DE and MDE for the optimization of reactor network design problem. Results are shown considering average best, worst, mean, median, and standard deviation of the optimum values of 25 runs. Though the experimental runs are taken for 500 numbers of generations, the comparison of results is carried out at intermediate numbers of functions evaluations (FES) ie. FES value of 10000, 15000, 20000, 50000 and 100000 (Corresponding to 50, 75, 100, 250 and 500 generations respectively). Taking standard deviation to be one of the measures of the effectiveness of any algorithm, it is observed that MDE produces better results than those obtained using DE. The consistency with which $\mathrm{DE}$ and MDE has performed is evident from the fact that standard deviation achieved a value of 0 (zero) or close to zero. Figure 6 shows that error reduces faster in MDE compared to DE. Table 7 shows FES, CPU time and function value for various problems using strategies of DE. MDE algorithm finds the global optimum in lesser number of FES than DE. The CPU time taken by MDE is much lesser compared to DE.

\section{Conclusion}

Binary interaction parameters of two wellknown activity coefficient models are calculated for 20 different extraction systems having ILS based on flash systems using Modified DE and genetic algorithms. The activity coefficient models parameters as well as the rmsd have been obtained and are reported. The MDE algorithm successfully converged to the global optimum having rmsd value of 0.0023 and 0.0170 for NRTL and Two-Suffix Margules models respectively for 169 tie-lines. The NRTL 
Table 4. The calculated parameters of NRTL and Two-Suffix Margules models for ternary systems listed in Table 1.

\begin{tabular}{|c|c|c|c|c|c|c|c|c|c|}
\hline \multirow[t]{3}{*}{ Sys. No } & \multirow{3}{*}{$\begin{array}{l}\text { Com. } \\
i-j\end{array}$} & \multicolumn{4}{|c|}{ Genetic Algorithm } & \multicolumn{4}{|c|}{ Differential Evolution (Present study) } \\
\hline & & \multicolumn{3}{|c|}{ NRTL } & \multirow{2}{*}{$\begin{array}{l}\text { Margules } \\
A_{i j}\end{array}$} & \multicolumn{3}{|c|}{ NRTL } & \multirow{2}{*}{$\begin{array}{l}\text { Margules } \\
A_{i j}\end{array}$} \\
\hline & & $A_{i j}$ & $A_{j i}$ & $a_{i j}$ & & $A_{i j}$ & $A_{j i}$ & $a_{i j}$ & \\
\hline \multirow[t]{3}{*}{1} & $1-2$ & 332.461 & -373.942 & 0.348 & 0.598 & 1808.666 & 245.915 & 0.318 & 0.550 \\
\hline & $1-3$ & 1229.120 & -0.160 & 0.317 & 1.970 & 2248.897 & 723.989 & 0.304 & 1.912 \\
\hline & $2-3$ & 2446.890 & 1302.380 & 0.167 & 31.003 & 1631.324 & 1402.217 & 0.258 & 17.380 \\
\hline \multirow[t]{3}{*}{2} & $1-2$ & 391.263 & -303.572 & 0.265 & 1.260 & 585.162 & 1184.298 & 0.500 & 3.055 \\
\hline & $1-3$ & 1892.510 & -460.185 & 0.282 & 2.543 & 1115.590 & 1147.705 & 0.485 & 4.006 \\
\hline & $2-3$ & 2067.940 & 494.310 & 0.160 & 30.618 & 1793.492 & 468.268 & 0.155 & 40.318 \\
\hline \multirow[t]{3}{*}{3} & $1-2$ & 1166.300 & -291.783 & 0.202 & 1.481 & 1253.989 & 616.033 & 0.344 & 1.481 \\
\hline & $1-3$ & 2287.100 & -183.950 & 0.181 & 1.954 & 1770.190 & 846.111 & 0.339 & 1.955 \\
\hline & $2-3$ & 2349.960 & 1661.440 & 0.399 & 7.870 & 2212.606 & 1168.640 & 0.249 & 7.874 \\
\hline \multirow[t]{3}{*}{4} & $1-2$ & 546.571 & -150.197 & 0.168 & 2.051 & 2.051 & 2.051 & 2.051 & 1.481 \\
\hline & $1-3$ & 2299.100 & -72.187 & 0.269 & 2.227 & 2.227 & 2.227 & 2.227 & 1.955 \\
\hline & $2-3$ & 2349.940 & 611.617 & 0.158 & 6.263 & 6.263 & 6.263 & 6.263 & 7.874 \\
\hline \multirow[t]{3}{*}{5} & $1-2$ & 2203.280 & 152.150 & 0.319 & 2.848 & 1450.995 & 228.000 & 0.468 & 2.848 \\
\hline & $1-3$ & 1414.250 & -19.610 & 0.262 & 2.880 & 1199.688 & 171.480 & 0.410 & 2.880 \\
\hline & $2-3$ & 1156.610 & 902.890 & 0.199 & 26.417 & 1627.191 & 1495.390 & 0.476 & 26.413 \\
\hline 6 & $1-2$ & 718.490 & -350.020 & 0.156 & 3.474 & 822.354 & 373.761 & 0.486 & 3.474 \\
\hline & $1-3$ & 1416.000 & -253.554 & 0.448 & 3.994 & 1007.923 & 237.460 & 0.490 & 3.994 \\
\hline & $2-3$ & 1630.430 & 570.194 & 0.274 & 6.982 & 2182.877 & 1171.958 & 0.392 & 6.982 \\
\hline 7 & $1-2$ & 1614.230 & -317.152 & 0.202 & -3.423 & 1317.259 & 348.606 & 0.393 & -3.421 \\
\hline & $1-3$ & 913.786 & 1647.690 & 0.340 & 2.320 & 886.443 & 822.118 & 0.393 & 2.321 \\
\hline & $2-3$ & 1999.940 & 1982.020 & 0.331 & 0.707 & 1996.124 & 780.712 & 0.393 & 0.708 \\
\hline 8 & $1-2$ & 841.486 & 1596.257 & 0.353 & 2.012 & 1256.108 & 2131.636 & 0.290 & 2.012 \\
\hline & $1-3$ & 1452.005 & 998.742 & 0.388 & 2.173 & 1431.010 & 1021.001 & 0.353 & 2.173 \\
\hline & $2-3$ & 1316.861 & 1018.664 & 0.317 & 8.219 & 2079.796 & 1749.430 & 0.452 & 8.219 \\
\hline 9 & $1-2$ & 741.522 & -211.792 & 0.275 & 2.111 & 477.960 & 2350.571 & 0.459 & 2.005 \\
\hline & $1-3$ & 1222.370 & 549.816 & 0.480 & 2.851 & 1398.317 & 602.968 & 0.47 & 3.208 \\
\hline & $2-3$ & 1672.420 & 1349.360 & 0.297 & 27.852 & 2126.787 & 537.834 & 0.153 & 50.000 \\
\hline 10 & $1-2$ & 694.667 & -388.136 & 0.172 & 3.326 & 337.318 & 2191.849 & 0.478 & 3.325 \\
\hline & $1-3$ & 1105.550 & -134.000 & 0.430 & 3.469 & 987.739 & 2022.673 & 0.490 & 3.468 \\
\hline & $2-3$ & 2200.000 & 1145.020 & 0.359 & 5.085 & 1920.268 & 952.934 & 0.325 & 5.084 \\
\hline 11 & $1-2$ & -204.989 & 704.990 & 0.170 & 2.285 & 350.795 & 503.925 & 0.404 & 2.285 \\
\hline & $1-3$ & 936.160 & 635.653 & 0.479 & 2.839 & 879.405 & 853.769 & 0.436 & 2.839 \\
\hline & $2-3$ & 1748.260 & 791.847 & 0.329 & 3.733 & 2375.034 & 978.002 & 0.335 & 3.733 \\
\hline 12 & $1-2$ & -200.378 & 438.288 & 0.206 & 1.854 & 857.393 & 623.613 & 0.392 & 1.457 \\
\hline & $1-3$ & 1741.060 & 108.973 & 0.305 & 2.443 & 2084.367 & 916.730 & 0.348 & 2.449 \\
\hline & $2-3$ & 1737.620 & 956.303 & 0.163 & 23.571 & 2205.090 & 917.315 & 0.176 & 50 \\
\hline 13 & $1-2$ & 905.115 & -272.115 & 0.171 & 1.256 & 1200.128 & 487.116 & 0.490 & 1.226 \\
\hline & $1-3$ & 2499.900 & 533.974 & 0.328 & 2.242 & 1579.257 & 635.045 & 0.376 & 2.300 \\
\hline & $2-3$ & 1839.160 & 1450.190 & 0.238 & 36.998 & 2124.391 & 1261.642 & 0.246 & 50.000 \\
\hline 14 & $1-2$ & 848.574 & 1072.305 & 0.455 & 2.833 & 665.977 & 814.838 & 0.498 & 2.832 \\
\hline & $1-3$ & 1109.720 & 1479.689 & 0.429 & 3.234 & 2389.324 & 944.450 & 0.393 & 3.234 \\
\hline & $2-3$ & 2499.746 & 1320.741 & 0.360 & 8.947 & 2137.053 & 1261.558 & 0.340 & 8.949 \\
\hline 15 & $1-2$ & 340.847 & 79.208 & 0.257 & 1.580 & 779.009 & 610.614 & 0.468 & 1.381 \\
\hline & $1-3$ & 1493.610 & 310.828 & 0.396 & 2.485 & 2036.159 & 805.412 & 0.372 & 2.523 \\
\hline & $2-3$ & 1989.530 & 720.570 & 0.161 & 37.999 & 1964.976 & 663.817 & 0.152 & 50.000 \\
\hline 16 & $1-2$ & 674.414 & -237.622 & 0.237 & 3.003 & 403.228 & 1668.606 & 0.496 & 3.003 \\
\hline & $1-3$ & 1257.920 & -235.265 & 0.393 & 3.540 & 1767.738 & 1507.400 & 0.476 & 3.540 \\
\hline & $2-3$ & 1632.750 & 644.722 & 0.347 & 5.327 & 2128.587 & 655.524 & 0.293 & 5.326 \\
\hline 17 & $1-2$ & 736.220 & -378.023 & 0.293 & 2.718 & 294.293 & 1909.581 & 0.403 & 2.718 \\
\hline & $1-3$ & 1669.349 & -361.050 & 0.306 & 2.982 & 2169.359 & 1729.861 & 0.413 & 2.982 \\
\hline & $2-3$ & 2143.899 & 436.847 & 0.240 & 5.921 & 1527.369 & 175.643 & 0.166 & 5.921 \\
\hline 18 & $1-2$ & 2045.840 & -190.682 & 0.174 & 2.383 & 1800.158 & 954.327 & 0.327 & 2.383 \\
\hline & $1-3$ & 1122.930 & 873.039 & 0.370 & 2.667 & 1301.322 & 1178.783 & 0.359 & 2.667 \\
\hline & $2-3$ & 2101.480 & 1110.080 & 0.440 & 4.883 & 796.140 & 522.945 & 0.480 & 4.882 \\
\hline 19 & $1-2$ & 719.628 & -251.316 & 0.174 & 1.428 & 705.099 & 325.113 & 0.418 & 1.428 \\
\hline & $1-3$ & 1422.290 & 475.905 & 0.389 & 2.730 & 2364.234 & 801.241 & 0.336 & 2.730 \\
\hline & $2-3$ & 2234.870 & 829.965 & 0.221 & 24.076 & 2078.687 & 572.206 & 0.172 & 24.083 \\
\hline 20 & $1-2$ & -250.213 & 815.750 & 0.170 & 1.880 & 804.410 & 744.982 & 0.425 & 1.929 \\
\hline & $1-3$ & 2308.960 & -96.792 & 0.187 & 2.295 & 1976.340 & 856.057 & 0.360 & 2.325 \\
\hline & $2-3$ & 1943.820 & 998.124 & 0.161 & 35.104 & 1931.866 & 1924.642 & 0.170 & 42.644 \\
\hline
\end{tabular}


Table 5. The results of rmsd obtained in this work using MDE, GA and other methods in literature.

\begin{tabular}{|c|c|c|c|c|c|}
\hline \multirow{4}{*}{ Sys. No. } & \multicolumn{3}{|l|}{ NRTL } & \multicolumn{2}{|c|}{ Margules } \\
\hline & Literature & GA & MDE & GA & MDE \\
\hline & & & This & & This Work \\
\hline & & & work & & \\
\hline 1 & 0.0021 & 0.0013 & 0.0006 & 0.0019 & 0.0018 \\
\hline 2 & 0.0155 & 0.0038 & 0.0028 & 0.0179 & 0.0139 \\
\hline 3 & 0.0029 & 0.0008 & 0.0006 & 0.0040 & 0.0040 \\
\hline 4 & 0.0050 & 0.0008 & 0.0011 & 0.0078 & 0.0078 \\
\hline 5 & 0.0236 & 0.0039 & 0.0035 & 0.0073 & 0.0073 \\
\hline 6 & 0.0041 & 0.0024 & 0.0036 & 0.0212 & 0.0212 \\
\hline 7 & 0.0443 & 0.0031 & 0.0013 & 0.0339 & 0.0339 \\
\hline 8 & 0.0020 & 0.0004 & 0.0016 & 0.0088 & 0.0087 \\
\hline 9 & 0.0160 & 0.0059 & 0.0027 & 0.0230 & 0.0227 \\
\hline 10 & 0.0065 & 0.0030 & 0.0029 & 0.0220 & 0.0219 \\
\hline 11 & 0.0280 & 0.0062 & 0.0046 & 0.0339 & 0.0338 \\
\hline 12 & 0.0050 & 0.0018 & 0.0010 & 0.0193 & 0.0184 \\
\hline 13 & 0.0096 & 0.0038 & 0.0010 & 0.0038 & 0.0032 \\
\hline 14 & 0.0145 & 0.0048 & 0.0024 & 0.0184 & 0.0184 \\
\hline 15 & 0.0051 & 0.0027 & 0.0019 & 0.0192 & 0.0187 \\
\hline 16 & 0.0157 & 0.0036 & 0.0037 & 0.0292 & 0.0291 \\
\hline 17 & 0.0188 & 0.0060 & 0.0046 & 0.0273 & 0.0272 \\
\hline 18 & 0.0359 & 0.0051 & 0.0041 & 0.0318 & 0.0317 \\
\hline 19 & 0.0090 & 0.0028 & 0.0011 & 0.0130 & 0.0130 \\
\hline 20 & 0.0108 & 0.0056 & 0.0009 & 0.0035 & 0.0033 \\
\hline Overall & 0.0159 & 0.0039 & 0.0023 & 0.0195 & 0.0170 \\
\hline
\end{tabular}

Table 6. Results obtained for RND problem using DE and MDE.

\begin{tabular}{lllllll}
\hline Algorithm & FES & Best & Worst & Mean & Median & Std-Dev \\
\hline DE & 10000 & 0.388811 & 0.388453 & 0.388789 & 0.388793 & $1.81 \mathrm{E}-05$ \\
& 15000 & 0.388811 & 0.388804 & 0.388811 & 0.388811 & $2.46 \mathrm{E}-07$ \\
& 20000 & 0.388811 & 0.388811 & 0.388811 & 0.388811 & $2.88 \mathrm{E}-09$ \\
& 50000 & 0.388811 & 0.388811 & 0.388811 & 0.388811 & 0 \\
MDE & 100000 & 0.388811 & 0.388811 & 0.388811 & 0.388811 & 0 \\
& 10000 & 0.388811 & 0.388723 & 0.388807 & 0.388806 & $4.62 \mathrm{E}-06$ \\
& 15000 & 0.388811 & 0.3811 & 0.388811 & 0.388811 & $2.92 \mathrm{E}-08$ \\
& 20000 & 0.388811 & 0.388811 & 0.388811 & 0.388811 & $2 \mathrm{E}-10$ \\
& 50000 & 0.388811 & 0.388811 & 0.388811 & 0.388811 & 0 \\
\end{tabular}

Table 7. Number of function evaluations (FES), CPU time and function value

\begin{tabular}{llll}
\hline Problem & & DE & MDE \\
\hline RND & $\begin{array}{l}\text { No. of function } \\
\text { Evaluations } \\
\text { CPU Time (s) }\end{array}$ & 14283 & 12699 \\
& Function Value (Cost) & 0.6388811 & 0.388811 \\
\hline
\end{tabular}




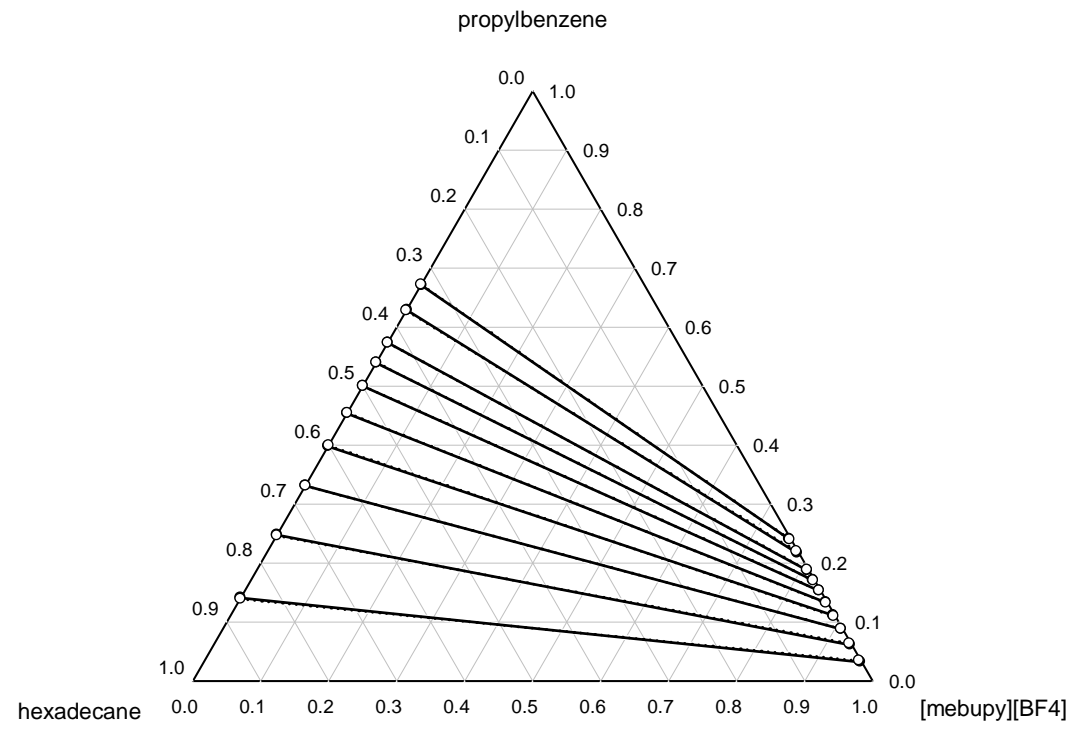

Figure 4. Tie-lines for system no. 1, NRTL model, solid lines and full points: predicted tie-lines with GA; dashed lines and empty points: predicted tie-lines with MDE.

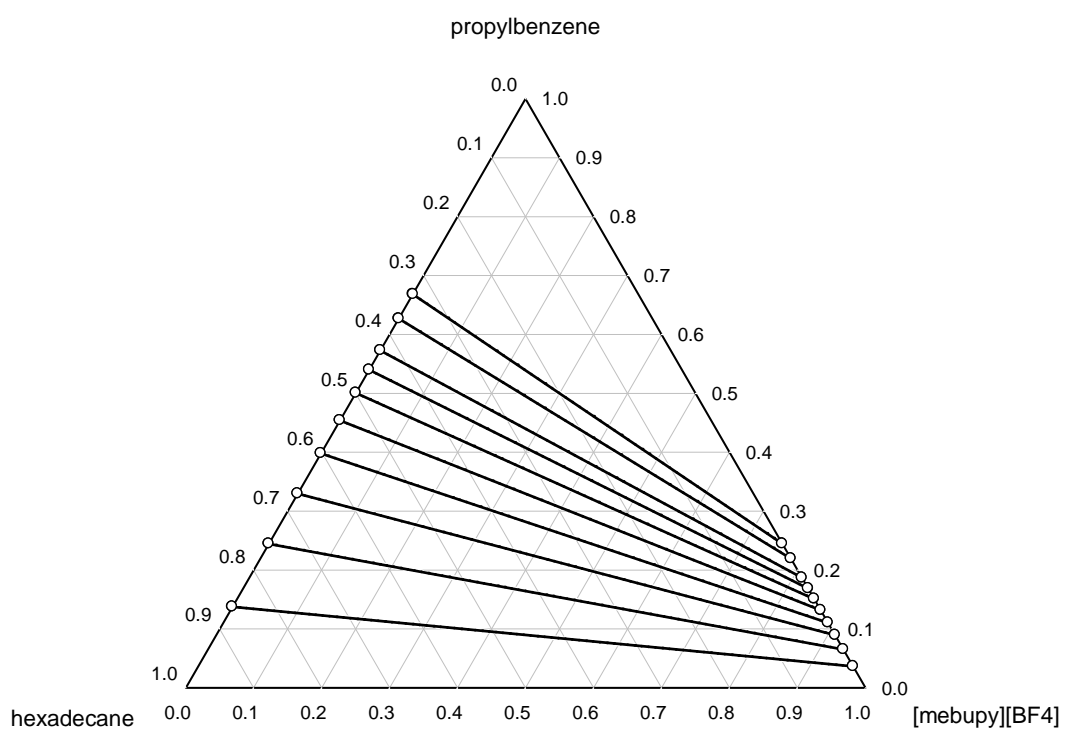

Figure 5. Tie-lines for system no. 1, Two-Suffix Margules model, solid lines and full points: predicted tie-lines with GA; dashed lines and empty points: predicted tie-lines with MDE.

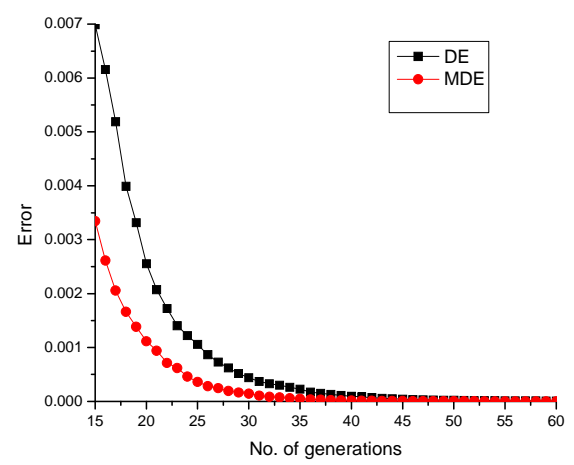

Figure 6. Error against number of generations for reactor network design problem. 
model outperformed the Two-Suffix Margules model by predicting more accurate (with one order of magnitude) rmsd values. The results obtained in this work using MDE are better compared to the results obtained using GA and other traditional algorithms. This study can be extended for the calculation of some other activity coefficient models using similar approach. For RND problem MDE algorithm outperforms DE in terms of number of function evaluations.

\section{Acknowledgment}

The authors are grateful to Petroleum and Chemical Engineering Department of Sultan Qaboos University for supporting this study.

\section{References}

Alkhaldi KHAE, Al-Tuwaim MS, Fandary MS, Al-Jimaz AS (2011), Separation of propylbenzene and n-alkanes from their mixtures using 4-methyl-N-butylpyridinium tetrafluoroborate as an ionic solvent at several temperatures. Fluid Phase Equilibria 309: 102107.

Al-Maamari RS, Vakili-Nezhaad G, Vatani M (2015), Experimental and modeling investigations of the viscosity of crude oil binary blends: New Models Based on the Genetic Algorithm Method. The Journal of Engineering Research 11: 81-91.

Angira R (2006), Evolutionary Computation for Optimization of Selected Non-linear Chemical Processes. Ph.D. Thesis (BITS-Pilani, India).

Angira R, Babu BV (2006), Optimization of process synthesis and design problems: A modified differential evolution approach. Chemical Engineering Science 61: 4707-4721.

Babu BV, Angira R (2006), Modified differential evolution (MDE) for optimization of nonlinear chemical processes. Computers and Chemical Engineering 30: 989-1002.

Colaco MJ, Dulikravich GS, Martin TJ (2004), optimization of wall electrodes for electrohydrodynamic control of natural convection during solidification. Materials and Manufacturing Processes 19: 719-736.

Dománska U, Pobudkowska A, Krolikowski M (2007), Separation of aromatic hydrocarbons from alkanes using ammonium ionic liquid C2NTf2 at $\mathrm{T}=298.15 \mathrm{~K}$. Fluid Phase Equilibria 259: 173-179.

Domínguez I, González EJ, González R, Domínguez A (2011), Extraction of benzene from aliphatic compounds using commercial ionic liquids as solvents: study of the liquidliquid equilibrium at $\mathrm{t}=298.15 \mathrm{~K}$. Journal of Chemical and Engineering Data 56: 3376-3383.

Fan HY, Lampinen J (2003), Trigonometric mutation operation to differential evolution. Journal of Global Optimization 27: 105-129.

García J, Fernández A, Torrecilla J, Oliet M, Rodríguez F (2009), Liquid-liquid equilibria for \{hexane + benzene + 1-ethyl-3methylimidazolium ethylsulfate) at (298.2, 313.2 and 328.2) K. Fluid Phase Equilibria 282: 117-120.

García J, Fernández A, Torrecilla J, Oliet M, Rodríguez F (2010a), Ternary liquid-liquid equilibria measurement for hexane and benzene with the ionic liquid 1-Butyl-3methylimidazolium methylsulfate at $\mathrm{T}=$ (298.2, 313.2, and 328.2) K. Journal of Chemical and Engineering Data 55: 258-261.

García J, García S, Torrecilla J, Oliet M, Rodríguez F (2010b), Liquid-liquid equilibria for the ternary systems Heptane + Toluene + N-Butylpyridinium Tetrafluoroborate or NHexylpyridinium Tetrafluoroborate $\}$ at $\mathrm{T}=$ 313.2 K. Journal of Chemical and Engineering Data 55: 2862-2865.

Gujarathi AM, Babu BV (2009a), Improved multi objective differential evolution (MODE) approach for purified terephthalic acid (PTA) Oxidation Process. Materials and Manufacturing Processes 24: 303-319.

Gujarathi AM, Babu BV (2009b), Optimization of adiabatic styrene reactor: A hybrid multi objective differential evolution (H-MODE) Approach. Industrial and Engineering Chemistry Research 48: 11115-11132.

Gujarathi AM, Babu BV (2010a), Advances in optimization and simulation of low density polyethylene (LDPE) tubular reactor. In Handbook of Research on Chemo informatics and Chemical Engineering, Edited by A K Haghi, Nova Science Publishers, USA 109-138.

Gujarathi AM, Babu BV (2010b), Multi-objective optimization of industrial styrene reactor: Adiabatic and pseudo-isothermal operation. Chemical Engineering Science 65: 2009-2026.

Gujarathi AM, Babu BV (2011), Multiobjective optimization of industrial processes using elitist multi objective differential evolution (Elitist-MODE). Materials and Manufacturing Processes 26: 455-463.

Gutierrez JP, Meindersma W, de Haan AB (2011), Binary and ternary (liquid + liquid) equilibrium for \{methylcyclohexane (1) + toluene (2) + 1-hexyl-3-methylimidazolium tetracyanoborate (3)/1-butyl-3methylimidazolium tetracyanoborate (3). The 
Journal of Chemical Thermodynamics 43: 16721677.

Hansmeier AR, Jongmans M, Meindersma GW, de Haan AB (2010a), LLE data for the ionic liquid 3-methyl-N-butyl pyridinium dicyanamide with several aromatic and aliphatic hydrocarbons. The Journal of Chemical Thermodynamics 42: 484-490.

Hansmeier AR, Minoves Ruiz M, Meindersma GW, de Haan AB (2010b), Liquid-liquid equilibria for the three ternary systems (3methyl-N-butylpyridinium dicyanamide + Toluene + Heptane), (1-Butyl-3methylimidazolium Dicyanamide + Toluene + Heptane) and (1-Butyl-3-methylimidazolium Thiocyanate + Toluene + Heptane) at $\mathrm{T}=$ (313.15 and 348.15) $\mathrm{K}$ and $\mathrm{p}=0.1 \mathrm{MPa}$. Journal of Chemical and Engineering Data 55: 708-713.

Holland JH (1992), Algoritmos geneticos. Investigacion Y Ciencia 192: 38-45.

Kirkpatrick S, Gelatt CD, Vecchi MP (1983), Optimization by simulated annealing. Science 220: 671-680.

Lei Z, Zhang J, Li Q, Chen B (2009), UNIFAC model for ionic liquids. Industrial and Engineering Chemistry Research 48: 2697-2704.

Letcher TM, Deenadayalu N (2003), Ternary liquid-liquid equilibria for mixtures of 1 methyl- 3 - octyl - imidazolium chloridepbenzenepan alkane at $\mathrm{T}=298.2 \mathrm{~K}$ and 1 atm. The Journal of Chemical Thermodynamics 35: 67-76.

Letcher TM, Reddy P (2005), Ternary (liquid+liquid) equilibria for mixtures of 1hexyl-3-methylimidazolium (tetrafluoroborate or hexafluorophosphate)+benzene+alkane at $\mathrm{T}=298.2 \mathrm{~K}$ and $\mathrm{p}=0.1 \mathrm{MPa}$. The Journal of Chemical Thermodynamics 37: 415-421.

Maduro RM, Aznar M (2008), Liquid-liquid equilibrium of ternary systems 1-butyl-3methylimidazolium hexafluorophosphate + aromatic + aliphatic. Fluid Phase Equilibria 265: 129-138.

Maduro RM, Aznar M (2010), Liquid-liquid equilibrium of ternary systems 1-octyl-3methylimidazolium hexafluorophosphate + aromatic + aliphatic hydrocarbons. Fluid Phase Equilibria 296: 88-94.

Pereiro AB, Rodriguez A (2009), Application of the ionic liquid Ammoeng 102 for aromatic/aliphatic hydrocarbon separation. The Journal of Chemical Thermodynamics 41: 951-956.
Prausnitz JM, Lichtenthaler RN, Azevedo EG (1999), Molecular thermodynamics of fluid phase equilibria, third ed., Prentice-Hall, New York.

Price KV, Storn RM, Lampinen JA (2005), Differential evolution: A practical approach to global optimization. Springer, Berlin Heidelberg.

Rashtchian D, Ovaysi S, Taghikhani V, Ghotbi C (2007), Application of the genetic algorithm to calculate the interaction parameters for multiphase and multicomponent systems. Iranian Journal of Chemistry and Chemical Engineering 26: 89-102.

Renon H, Prausnitz J M (1968), Local compositions in thermodynamic excess functions for liquid mixtures. AIChE Journal 14: 135-144.

Revelli AL, Mutelet F, Jaubert JN (2010), Extraction of benzene or thiophene from nheptane using ionic liquids. NMR and thermodynamic study. The Journal of Physical Chemistry B 114: 4600-4608.

Ryoo HS, Sahinidis NV (1995), Global optimization of nonconvex NLPs and MINLPs with applications in process design. Computers and Chemical Engineering 19: 551-566.

Sahoo RK, Banerjee T, Ahmad SA, Khanna A (2006), Improved binary parameters using GA for multi-component aromatic extraction: NRTL model without and with closure equations. Fluid Phase Equilibria 239: 107-119.

Sahoo RK, Banerjee T, Khanna A (2007), UNIQUAC interaction parameters with closure for imidazolium based ionic liquid systems using genetic algorithm. The Canadian Journal of Chemical Engineering 85: 833-853.

Seader JD, Henley E J (2006), Separation process principles, second ed., John Wiley and Sons, Inc., New York.

Selvan MS, McKinley MD, Dubois RH, Atwood JL (2000), Liquid-liquid equilibria for toluene + heptane + 1-Ethyl-3-methylimidazolium triiodide and toluene + heptane + 1-Butyl-3methylimidazolium triiodide. Journal of Chemical and Engineering Data 45: 841-845.

Singh MK, Banerjee T, Khanna A (2005), Genetic algorithm to estimate interaction parameters of multicomponent systems for liquid-liquid equilibria. Computers and Chemical Engineering 29: 1712-1719. 
Stragevitch L, Davila SG (1997), Application of a generalized maximum likelihood method in the reduction of multicomponent liquid-liquid equilibrium data. Brazilian Journal of Chemical Engineering 14: 41-52.

Stumberger G, Dolinar D, Pahner U, Hameyer K (2000), Optimization of radial active magnetic bearings using the finite element technique and the differential evolution algorithm. IEEE Transactions on Magnetics 36: 1009-1013.

Vakili-Nezhaad G, Vatani M, Asghari M (2013), Calculation of the binary interaction and nonrandomness parameters of NRTL, NRTL1, and NRTL2 models using genetic algorithm for ternary ionic liquid systems. Chemical Engineering Communications 200: 1102-1120.

Vakili-Nezhaad G, Vatani M, Gujarathi AM (2014), Application of genetic algorithm to calculation of three-suffix margules parameters in ternary extraction ionic liquid systems. International Journal of Thermodynamics 17: 1-6.

Vatani M, Asghari M, Vakili-Nezhaad G (2012), Application of genetic algorithm to the calculation of parameters for NRTL and twosuffix margules models in ternary extraction ionic liquid systems. Journal of Industrial and Engineering Chemistry 18: 17151720.

Zhou T, Wang Z, Chen L, Ye Y, Qi Z, Freund H, Sundmacher K (2012), Evaluation of the ionic liquids 1-alkyl-3-methylimidazolium hexafluorophosphate as a solvent for the extraction of benzene from cyclohexane: (Liquid + liquid) equilibria. The Journal of Chemical Thermodynamics 48: 145-149. 